University of Nebraska - Lincoln

DigitalCommons@University of Nebraska - Lincoln

May 2004

\title{
Assessing the efficacy of registered underground baiting products for mountain beaver (Aplodontia rufa) control
}

Wendy M. Arjo

USDA/APHIS/WS/National Wildlife Research Center

Dale L. Nolte

USDA-APHIS-Wildlife Services, Dale.L.Nolte@aphis.usda.gov

Follow this and additional works at: https://digitalcommons.unl.edu/icwdm_usdanwrc

Part of the Environmental Sciences Commons

Arjo, Wendy M. and Nolte, Dale L., "Assessing the efficacy of registered underground baiting products for mountain beaver (Aplodontia rufa) control " (2004). USDA National Wildlife Research Center - Staff Publications. 72.

https://digitalcommons.unl.edu/icwdm_usdanwrc/72

This Article is brought to you for free and open access by the U.S. Department of Agriculture: Animal and Plant Health Inspection Service at DigitalCommons@University of Nebraska - Lincoln. It has been accepted for inclusion in USDA National Wildlife Research Center - Staff Publications by an authorized administrator of DigitalCommons@University of Nebraska - Lincoln. 


\title{
Assessing the efficacy of registered underground baiting products for mountain beaver (Aplodontia rufa) control
}

\author{
Wendy M. Arjo*, Dale L. Nolte \\ USDA/APHIS/WS/National Wildlife Research Center, 9730-B Lathrop Industrial Drive, SW, Olympia, WA 98512, USA
}

Received 6 December 2002; received in revised form 8 September 2003; accepted 9 September 2003

\begin{abstract}
The mountain beaver (Aplodontia rufa) is a fossorial rodent species endemic to the Pacific Northwest and portions of California. This herbivore inflicts millions of dollars of damage annually to forest seedling plantations. Currently, extensive trapping prior to planting is the most reliable method for reducing damage. With increasing restrictions placed on trapping, forest resource managers need alternative tools to minimize forest damage. This study assessed the potential of four toxicants registered for underground use to control mountain beaver; zinc phosphide, diphacinone, chlorophacinone, and strychnine. Zinc phosphide and strychnine are acute toxicants, whereas diphacinone and chlorophacinone are anticoagulants. Anticoagulants prevent the recycling of vitamin $\mathrm{K}$ in the body, which inhibits the production of clotting factors. Efficacy varied among treatments. Zinc phosphide and strychnine were avoided by mountain beaver. Pre-baiting marginally increased acceptance of strychnine, but did not alter mountain beaver acceptance of zinc phosphide. Diphacinone and chlorophacinone were both readily consumed, but only chlorophacinone was $100 \%$ effective after a 14-day baiting regime. Subsequently, we tested the effects of diet on the efficacy of diphacinone by varying the availability of food containing vitamin $\mathrm{K}$, the anticoagulant antidote. Restricting access to potential sources of vitamin $\mathrm{K}$ appeared to increase efficacy. We conclude that anticoagulants hold some promise as additional tools for managers to reduce mountain beaver populations with chlorophacinone showing the most promise. However, limitations to anticoagulant baits include the necessity of long-term baiting (greater than 10 days), a possible decrease in toxicity if baits contact moisture, and potential primary hazards.

Published by Elsevier Ltd.
\end{abstract}

Keywords: Aplodontia rufa; Chlorophacinone; Diphacinone; Efficacy; Mountain beaver; Strychnine; Zinc phosphide

\section{Introduction}

Successful regeneration of conifers in the Pacific Northwest is limited by damage caused by various rodent species (Borrecco and Anderson, 1980; Black and Lawrence, 1992). Mountain beaver (Aplodontia rufa) cause more damage to Douglas-fir (Pseudotsuga menziesii) seedlings and saplings than any other mammal in the Pacific Northwest (Caffereta, 1992). Clipped seedlings, clipped lateral branches and tops of young trees, girdled bases and undermined roots are all examples of types of damage inflicted by this rodent. A survey in 1979 estimated that 0.1 million hectares of trees were damaged by mountain beaver in Washington, Oregon, and northern California. On Douglas-fir stands alone in the Pacific Northwest region, it is estimated that more

\footnotetext{
*Corresponding author. Tel.: + 1-360-705-4565; fax: + 1-360-534-9755.

E-mail address: wendy.m.arjo@aphis.usda.gov (W.M. Arjo).
}

than 121,500 ha are adversely affected by mountain beaver (Evans, 1987). Mountain beaver are therefore managed as pests and are economically important because of the damage they cause to reforestation projects (Hooven, 1977; Borrecco and Anderson, 1980; Campbell and Evans, 1988).

Forest managers have had access to several tools for controlling mountain beaver populations in the past. Although box-traps can be used, efficacy is low and cost is high. Individual tree protectors are available, but again efficacy is marginal. Fencing to exclude mountain beaver from an area is impractical on plantation sites and is cost prohibitive (Nolte, 1998). Thus, lethal methods have generally been used to suppress populations. Conibear and leg-hold traps have been used, with the Conibear being the preferred trap; however, Conibear traps have been banned in Washington. Other approaches used in the past have included a toxic tracking foam incorporating octamethylpyro-phosphoramide (Evans, 1987), strychnine placed on native 
vegetation or apples (Nelson, 1969), and strychninebased Boomer-Rid. Although efficacy was questionable, Boomer-Rid was registered for use in Oregon (Orco Boomer-Rid mountain beaver bait SLN Reg. No. OR840029; Caffereta, 1992; Campbell et al., 1992).

Currently, most managers rely on Conibear traps in Oregon, while leg-hold traps are the only feasible method available to Washington managers. However, trapping also can be expensive. Trapping costs incurred at the Weyerhaeuser Twin Harbor Tree Farm averages \$40/acre with a $24 \mathrm{~h}$ trap check (J. Todd, pers. comm.). Effort to effectively trap a site varies but generally requires between 5 and 14 days. Given anti-trapping sentiment of at least some sections of the public the future of trapping may be questionable, and managers may be left with no reasonable options to protect seedlings from mountain beaver. Alternative measures, therefore, need to be explored.

At present there are no toxicants registered for use to control mountain beaver. Complying with data requirements necessary to register a new product with the Environmental Protection Agency (EPA) is an expensive and time-consuming process. However, it may be possible to add mountain beaver to an existing label if a product registered for underground baiting of rodents was determined to be effective. Four toxicants are currently registered to be applied in underground rodent burrows to protect agriculture crops: $0.5 \%$ strychnine, $2.0 \%$ zinc phosphide, $0.005 \%$ chlorophacinone, and $0.005 \%$ diphacinone. A series of tests was conducted to assess mountain beaver acceptance and subsequent fate when offered bait containing these four toxicants.

\section{Materials and methods}

\subsection{Subjects}

Forty mountain beaver were captured from the Capital Forest near Olympia, Washington, and housed at the National Wildlife Research Center Olympia Field Station. Mountain beaver were penned individually in covered outdoor pens $\left(3 \times 3 \mathrm{~m}^{2}\right)$ consisting of three 76-1 barrows with lids connected with perforated plastic pipe $(10 \mathrm{~cm}$ diameter). The barrows represented a nest structure and associated chambers common in mountain beaver burrows. Animals were given a minimum of 2-4 weeks to adapt to the pen and nest system. Subjects had free access to water, rodent blox (Animal Specialties, Hubbard, Oregon), and alfalfa cubes, and were provided an eighth of an apple daily. During the study, diets for mountain beaver varied as described below.

\subsection{Procedure for screening toxicants}

Twenty-five animals were randomly selected for the initial screening of the four toxicants. Five of the animals received bait containing $0.5 \%$ strychnine, five received $2.0 \%$ zinc phosphide, five received $0.005 \%$ chlorophacinone, and five received $0.005 \%$ diphacinone, while the remaining five animals served as controls and were given no toxicant. Baits were formulated with rolled oats and control animals were given untreated oats. Animals were offered baits in trays placed inside an additional barrow (761) located in the corner of each pen. Mountain beaver had access to bait through a $10 \mathrm{~cm}$ diameter hole at the bottom of each barrow. Zinc phosphide and strychnine are acute toxicants, where as the anticoagulants (diphacinone and chlorophacinone) are slower to act. Therefore, we offered animals zinc and strychnine treatments for 10 consecutive days, while anticoagulants were offered for 28 consecutive days. All animals received similar maintenance diets of rodent blox (Animal Specialties, Hubbard, Oregon), alfalfa cubes, and one-eighth-apple daily.

\subsection{Effects of diet on diphacinone efficacy}

Anticoagulants disrupt recycling of vitamin $\mathrm{K}$ reducing blood clotting and causing damage to capillaries (Silverman, 1980). Supplemental vitamin K can serve as an antidote. Since alfalfa and rodent blox contain vitamin $\mathrm{K}$, a second experiment was conducted to determine whether base diets affected mountain beaver response to diphacinone. All animals were offered oats treated with $0.005 \%$ diphacinone for 28 consecutive days. Data from the five animals from the initial toxicant screening of diphacinone with the maintenance diet were compared to two different diet regimes. Five subjects were given an ad libitum natural vegetation diet including salal (Gaultheria shallon), sword fern (Polystichum munitum), and bracken fern (Pteridium aquilinum), along with a chopped apple supplement. Another five animals were given rodent blox and apples but no alfalfa. Five animals served as controls received the maintenance diet fed during prior trials.

\subsection{Testing efficacy of pre-baiting}

Animals may avoid zinc phosphide or strychnine initially because of distinctive taste, or conditioning may occur if sub-lethal dosages are ingested during first encounters. We tested whether pre-baiting animals with untreated rolled-oats would increase later consumption of zinc phosphide and strychnine treated baits. Animals used as controls in both the screening test and the diphacinone diet test became the test subjects. After 28 days of pre-baiting with oats, five animals were presented with $2.0 \%$ zinc phosphide and five with $0.5 \%$ strychnine for 5 consecutive days to determine the benefits of pre-baiting. Maintenance diets were similar to those previously described. 


\subsection{Data collection and statistical analysis}

Baits were placed in pens each morning at approximately $0900 \mathrm{~h}$. Mountain beaver status was monitored at 2 -h intervals for the first $6 \mathrm{~h}$, then again at $24 \mathrm{~h}$. The previous day's baits were collected the following morning and replaced with fresh bait. We measured the daily amount of bait consumed (to the nearest $0.01 \mathrm{~g}$ ) by each mountain beaver. We considered bait that was spilled outside the barrow as "consumed". Any animal demonstrating severe symptoms (e.g., convulsions, comatose) during status checks was euthanatized immediately. All animal care and use for this study was approved by National Wildlife Research Center's Institutional Animal Care and Use Committee, protocol numbers 885 and 977.

A Fisher's exact test $(\mathrm{SAS} \AA$ Version 8.0, SAS institute Inc., Cary, N.C.) was used to test for differences in mortality between the four toxicants. We used a student's $t$-test to assess consumption differences of bait per gram animal body weight between subjects exposed to pre-baiting and those without a pre-bating regime prior to being offered zinc phosphide and strychnine baits. A Fisher's exact test was used to determine whether pre-baiting affected mortality. A single-factor analysis of variance (ANOVA) was used to assess differences among subjects fed varied daily rations when offered diphacinone treated baits.

\section{Results}

\subsection{Efficacy of screened toxicants}

Efficacy varied among the four baits $(P=0.008)$. No animals succumbed to zinc phosphide, even when some individuals ingested $>30 \mathrm{mg}$ of bait over a 5 -day period (Table 1). Although $80 \%$ of the animals sampled the zinc phosphide the first day (Fig. 1), only $60 \%$ ate any bait on than one subsequent day, with only one animal consuming $>50 \mathrm{mg}$. Strychnine was more effective, $60 \%$ of animals exposed to strychnine died during the 10-day test. Intake rates and toxicity varied among animals

Table 1

Comparison of average ( \pm s.d.) consumption rates (mg toxicant $/ \mathrm{kg}$ body wt.) and efficacy of four under-ground toxicants on mountain beaver

\begin{tabular}{llll}
\hline & Consumption & Days alive & $\%$ Mortality \\
\hline Zinc phosphide & $26.62 \pm 16.34$ & 28 & 0 \\
Strychnine & $5.6 \pm 6.1$ & $7.33 \pm 3.56$ & 60 \\
Dipahcinone & $3.94 \pm 2.41$ & $26 \pm 2$ & 20 \\
Chlorophacinone & $2.13 \pm 0.4$ & $12 \pm 1.73$ & 100 \\
\hline
\end{tabular}

Results are for 10 days of baiting with zinc phosphide and strychnine, and 28 days of baiting with diphacinone and chlorophacinone.

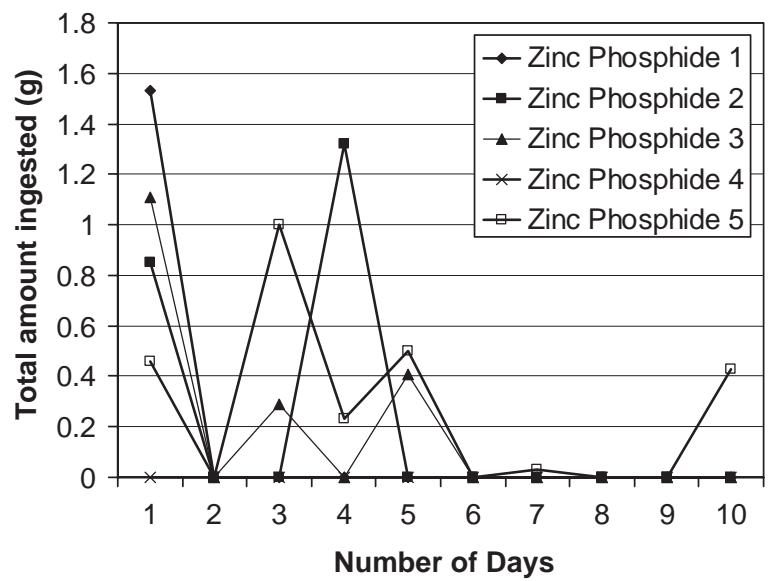

Fig. 1. Daily consumption rates of zinc phosphide-treated oats by five mountain beaver.

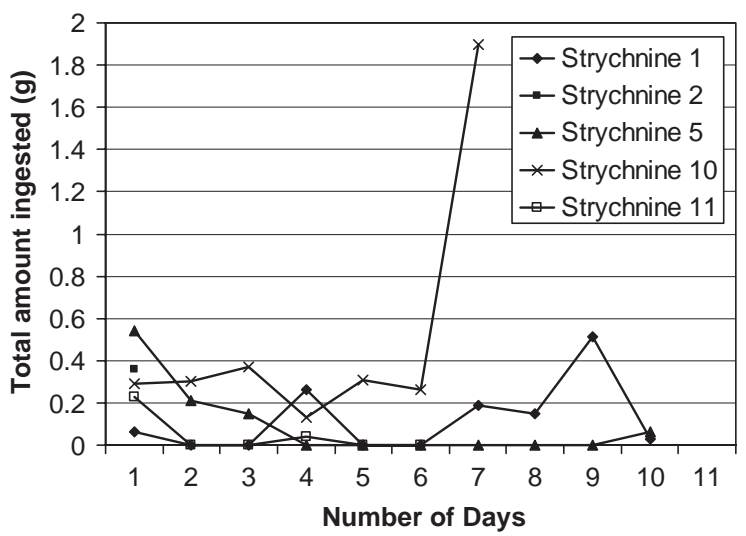

Fig. 2. Daily consumption rates of strychnine-treated oats by five mountain beaver.

(Fig. 2). Some animals succumbed after ingesting $1.13 \mathrm{mg} / \mathrm{kg}$ body weight while other subjects tolerated doses of $4 \mathrm{mg} / \mathrm{kg}$ body weight over the 10-day period. Diphacinone was readily consumed by $80 \%$ of the mountain beaver throughout the study; however, only one animal died after 28 days of continuous baiting. Average ingestion of bait was $3.94 \pm 2.41$ (s.d.) $\mathrm{mg} / \mathrm{kg}$ over the study. Chlorophacinone also was readily ingested by mountain beaver. One mountain beaver was euthanized after 10 days of baiting after exhibiting signs of chlorophacinone poisoning (i.e. bleeding from mouth, gasping for breath, and convulsions). In addition, the other four animals exposed to chlorophacinone died within 15 days. Although the exposed dosage was similar to, mean intake of chlorophacinone was $2.13 \pm 0.40 \mathrm{mg} / \mathrm{kg}$ of body weight before the animals died. Oats were readily ingested by all control animals.

\subsection{Effects of diet on diphacinone efficacy}

Mortality rate varied depending on maintenance diet fed mountain beaver while they were offered diphacinone bait (Table 2). Efficacy of the anti-coagulant 
Table 2

Effects of mountain beaver diet on efficacy of diphacinone anticoagulant rodenticide

\begin{tabular}{llll}
\hline & Consumption & Days alive & $\%$ Mortality \\
\hline Captive diet & $3.94 \pm 2.41$ & $26 \pm 2$ & 20 \\
Natural diet & $3.57 \pm 1.11$ & $21.2 \pm 1.98$ & 80 \\
No alfalfa diet & $2.15 \pm 0.94$ & $20 \pm 3.58$ & 60 \\
\hline
\end{tabular}

Average consumption ( \pm s.d.) of toxicants is listed as $\mathrm{mg} / \mathrm{kg}$ of body weight.

increased when probable sources of vitamin K (alfalfa or rodent blox) were removed. Four of the 5 animals maintained on the natural diet died, while 3 animals maintained on rodent blox without alfalfa died, but only 1 of the animals fed rodent blox and alfalfa died. The single animal on the natural diet that did not die from ingesting diphacinone bait had consumed the greatest amount of bait per body weight $(5.31 \mathrm{mg} / \mathrm{kg})$, demonstrating physiological tolerance variation the species. Although differences in efficacy were observed, they were not statically significant between diets $(P=0.3)$, probably due to small sample size. Diphacinone consumption among animals fed different diets was similar $\left(F_{2,12}=1.69, P=0.22\right)$. Regardless of diet, an extended exposure (16-22 days) was observed before any subject succumbed to diphacinone bait.

\subsection{Efficacy of pre-baiting for zinc phosphide and strychnine}

Pre-baiting did not affect $(P=0.56)$ mountain beaver acceptance of zinc phosphide or strychnine treated baits. Again, $80 \%$ of the animals sampled the zinc phosphide bait on the first day, but only one animal ate the bait on subsequent days. No animals, regardless whether prebaiting was practiced, died after ingesting zinc phosphide. Pre-baiting did not increase consumption rates for zinc phosphide bait $(t=0.82,8 \mathrm{df}, P=0.23$ ). Prebaiting also did not alter consumptions rates for strychnine bait $(t=-0.67,8 \mathrm{df}, P=0.26)$. All animals, regardless of pre-baiting regime, ingested strychninetreated bait on at least one day. However, $20 \%(n=1)$ fewer pre-baited animals survived the trial relative to animals not pre-baited. The smallest animal $(950 \mathrm{~g})$ tested, died the first day after consuming only $0.36 \mathrm{~g}$ of oats containing strychnine.

\section{Discussion}

Mountain beaver responded differently to the toxicants tested. They failed to ingest lethal dosages of bait containing zinc phosphide, and their consumption of strychnine bait was minimal. These results are similar to prior studies where zinc phosphide was regarded as ineffective because animals generally avoided the bait after ingesting sub-lethal amounts on first encounter (Campbell and Evans, 1988). Although, an initial test indicated potential efficacy of the strychnine-based product Boomer-Rid (Campbell and Evans, 1988), during subsequent field trials this product's efficacy was not consistent (Caffereta, 1992; Campbell et al., 1992). To our knowledge, field testing of $0.5 \%$ strychnine oats has not been conducted for mountain beaver.

Avoidance of bait may have been an initial response or animals may have developed bait shyness. Zinc phosphide has a distinctive taste and mountain beaver may be simply avoiding this taste. However, acute toxicants, such as zinc phosphide and strychnine, also can induce bait-shyness (Bhardwaj and Prakash, 1984). When rodents encounter new foods they often sample sparingly which can result in non-lethal amounts of bait being ingested (Buckle et al., 1987). Flavors are quickly associated with gastro-intestinal distress induced by the toxicants and a conditioned aversion is formed (Hadler and Buckle, 1992).

Pre-baiting is a preemptive measure to improve bait consumption, increasing the likelihood that rodents will ingest lethal amounts on first contact (Record and Marsh, 1988). Pre-baiting during our trials, however, had no apparent effect on subsequent bait consumption, and marginal impact on efficacy to control mountain beaver. Only one additional animal died after prebaiting than succumbed to strychnine bait in the absence of pre-baiting. Our pre-baiting period was extensive; 28 days is longer than practical for an operational baiting regime. The 10-day baiting period also is probably longer than operationally feasible. Pre-baiting may increase non-target species' exposure to toxicants. Animals that are accustomed to receiving food on a regular basis with minimal effort, as with pre-baiting at bait stations, are likely to continue to visit those stations, even after the food is changed from oats to toxicant baits. Therefore, the speed and or amount of bait consumed is likely increased with pre-baiting (Record and Marsh, 1988). Although baiting will be limited to underground use, a variety of non-target species occupy mountain beaver burrows (Feldhamer and Rochelle, 1994). Therefore, given the marginal efficacy, effort required, and possible non-target risks these results do not support incorporating zinc phosphide or strychnine in baits for controlling mountain beaver.

Anticoagulants are an alternative to acute toxicants. Advantages include their relatively short half-life in animals and a delay between ingestion and onset of symptoms, reducing the likelihood animals will develop bait shyness (Hadler and Buckle, 1992). Anticoagulants work by blocking the epoxide reductase enzyme inhibiting recycling of Vitamin K (Silverman, 1980). Without sufficient incoming vitamin $\mathrm{K}$ the ability to 
produce clotting factors is inhibited and hemorrhaging begins (Hadler and Buckle, 1992). Repeated exposure often is necessary before animals ingest a lethal dose. Although single dose anticoagulants are available, first generation anticoagulants like diphacinone and chlorophacinone are more effective if administered in small doses over a period of time (Hadler and Buckle, 1992).

Mountain beaver within this study readily consumed bait containing diphacinone or chlorophacinone. One animal did not accept bait treated with diphacinone, otherwise animals ate all $(5.0 \mathrm{~g})$ of the bait offered daily. Although most animals ingested diphacinone, only one individual died after 28 days exposure while on the captive diet. Campbell and Evans (1988) also reported poor efficacy to control mountain beaver populations using diphacinone bait blocks. Mountain beaver appeared more vulnerable to chlorophacinone; all animals died within 15 days. Total amount of active ingredient ingested was less for chlorophacinone than diphacinone, primarily because increased efficacy of chlorophacinone reduced number of potential exposures since animals died within 15 days of initial exposure. The amount ingested, however, is indicative of mountain beavers' tolerance for diphacinone relative to chlorophacinone under the presented maintenance diet. Nearly twice the amount of diphacinone $(3.94 \pm 2.41 \mathrm{mg} / \mathrm{kg})$ was consumed than chlorophacinone $(2.13 \pm 0.4 \mathrm{mg} / \mathrm{kg})$, and only one individual died after 28 days compared to all animals within 15 days. The $\mathrm{LD}_{50}$ for diphacinone for rats ranges from 3.0 to $17.0 \mathrm{mg} / \mathrm{kg}$ body weight which is comparable to that of chlorophacinone (Timms, 1994). There is considerable species variation reported for $\mathrm{LD}_{50}$ and mountain beaver may have a higher physiological tolerance for diphacinone than other rodents. Maintenance diets during our trials also included sources of vitamin $\mathrm{K}$, which may have increased their tolerance for either anticoagulant.

Green plant material may contain adequate Vitamin $\mathrm{K}$ to serve as an antidote to counter the effects of anticoagulants (Lowenthal and Rivera, 1979). Maintenance diet in this study included rodent blox and alfalfa, both known sources of vitamin K. Efficacy of diphacinone was increased when these food sources were removed during exposures. The test was not repeated with chlorophacinone because there was no reason to believe removing the source of vitamin $\mathrm{K}$ would reduce morbidity and efficacy was $100 \%$ during the initial test. Abundance of vitamin $\mathrm{K}$ in natural foods consumed by mountain beaver is unknown. However, the test diet regime included most common dietary foods, therefore, it is probably reflective of operational baiting conditions.

Registration costs, even for adding mountain beaver to existing labels, can be costly. Although three of the underground baits tested, strychnine, diphacinone, and chlorophacinone, showed some efficacy, we feel that chlorophacinone shows the most promise as a toxicant applicable for controlling mountain beaver. Strychnine did prove marginally effective; however, there are increased primary and secondary toxicant concerns when dealing with acute toxicants, and "Boomer rid" was a strychnine-based toxicant already shown to be ineffective. Even though diphacinone had a high efficacy under the natural diet, extending exposure (16-22 days) may prove prohibitive for operational baiting. The toxicant must constitute a large portion of the rodent's diet over an extended period, and most bait formulations do not last more than a few days in contact with moisture (Tickes et al., 1980). This test paradigm offered new baits to mountain beaver for approximately 28 consecutive days. Similar repeated baiting would not be practical in the field. Less frequent, but more bait per baiting, may increase feasibility, and is currently being pursued. However, baits placed in mountain beaver burrows are unlikely to persist more than a few days due to high moisture content.

Extended baiting periods could increase the potential for non-target exposure to the bait. Non-target species must be exposed to baits and the baits must be palatable for primary poisoning to occur (Kaukeinen et al., 2000). Several species other than mountain beaver frequent mountain beaver burrow systems (Feldhamer and Rochelle, 1994), and species, such as rabbits (Sylvilagus sp.), weasels (Mustela sp.), and skunks (Spilogale putorus and Mephitis mephitis), may likely consume baits. However, if a one-time baiting period could be found effective this could reduce the primary hazard risk and increase the feasibility of field operations. In addition, it is probable a delivery system which can be developed would encourage mountain beaver to cache baits further reducing non-target risks. Using an oatbased baits may reduce the chances of primary hazards to mustelids due to their avoidance of grain-based baits (Richardson, 1995 cited in Murphy et al., 1998). The shift to the use of anticoagulant rodenticides from acute rodenticides is due in part because they are considered less hazardous to wildlife (Blis et al., 1985; Hosea, 2000). Anticoagulants are rapidly eliminated from the body through excretion and metabolism, with only a fraction remaining bound in the liver (Record and Marsh, 1988; Hosea, 2000). A ten-fold dilution in anticoagulant concentration occurs through secondary exposure (Merson et al., 1984 in Kaukeinen et al., 2000). The final risk to the predator from poisoned carcasses is then diluted further as the predator eats non-poisoned prey as well (Kaukeinen et al., 2000). However, due to the long latent period (time between ingestions and onset of symptoms), more time is available to increase residuals in the body from continuous bait consumption (Record and Marsh, 1988). Several studies site low non-target effects from anticoagulants (Clark, 1978; Nemdenhall and Pank, 1980; Kaukeinen, 1982). Data collected from 
California (1994-1999) showed that $69 \%$ of the animals examined had been exposed to anticoagulants (Hosea, 2000; Kaukeinen et al., 2000); however, only 10-20\% showed clinical signs of coagulopathy (Kaukeinen et al., 2000). The impact of anticoagulants on the other 80 $90 \%$ could not be determined. Similar results were found in New York where $80 \%$ of the carcasses examined contained anticoagulants, but they could not be linked to the final cause of death.

Although chlorophacinone was found effective on mountain beaver, it is considered the least toxic to mammals of the four frequently used anticoagulants: diphacinone, bromadiolone, brodifacaum, and chlorophacinone (Hosea, 2000). Operational assessments will be necessary to further define the potential of chlorophacinone as a tool to control mountain beaver populations. In the interim, although trapping is expensive and time consuming, it remains the most feasible available method for controlling mountain beaver populations. Alternatives need to be explored and chlorophacinone baiting may be a necessary future tool for managers if other proven methods, such as trapping, are eliminated.

\section{References}

Bhardwaj, D., Prakash, I., 1984. Efficacy of three anticoagulant rodenticides for the control of poison-shy Rattus rattus. In: Clark, D.O. (Ed.), Proceedings of the 11th Vertebrate Pest Conference, 6-8 March 1984. Vol. 11, Sacramento, CA, pp. 82-83.

Black, H.C., Lawrence, W.H., 1992. Animal damage management in Pacific Northwest Forest: 1900-1990. In: H.C. Black (Ed.), Silvicultural Approaches to Animal Damage Management in Pacific Northwest Forests. US Department of Agriculture F.S. PNRS, Portland, OR, Gen. Tech. Rep. PNW-GTR-287, pp. 23-55.

Blis, L.J., Henny, C.J., Grove, R.A., 1985. Effects of palletized anticoagulant rodenticides on California quail. J. Wildl. Dis. 21, 391-395.

Borrecco, J.E., Anderson, R.J., 1980. Mountain beaver problems in the forests of California, Oregon, and Washington. In: Clark, J.P. (Ed.), Proceedings of the 10th Vertebrate Pest Conference, 4-6 March 1980. Vol. 10, Fresno, CA, pp. 135-142.

Buckle, A.P., Odam, E.M., Richards, C.J.G., 1987. Chemical bait markers for the study of bait uptake by Norway rats. In: Richards, C.G.J., Ku, T.Y. (Eds.), Control of mammal pests. Taylor and Francis, London, 406pp.

Caffereta, S., 1992. Silvicultural methods in relation to selected wildlife species. In: Black, H.G. (Ed.), Silvicultural approaches to animal damage management in Pacific Northwest Forests. USDA Forest Service Pacific Northwest Research Station Tech. Rep. PNW-GTR-287, pp. 231-251.

Campbell, D.L., Evans, J., 1988. Recent approaches to controlling mountain beavers (Aplodontia rufa) in Pacific Northwest forests. In: Crabb, A.C., R.E. Marsh (Eds.), Proceedings of the 13th Vertebrate Pest Conference, 1-3 March 1988. Vol. 13, Monterey, California. pp. 183-187.

Campbell, D.L., Farley, J.P., Engeman, R.M., 1992. Field efficacy evaluation of pelleted strychnine baits for control of mountain beaver (Aplodontia rufa). In: Borrecco, J., Marsh, R.E. (Eds.),
Proceedings of the 15th Vertebrate Pest Conference, 3-5 March 1992. Vol. 15, Newport Beach, CA, pp. 335-339.

Clark, D.O., 1978. Control of ground squirrels in California using anticoagulant treated baits. In: Howard, W.E., Marsh, R.E. (Eds.), Proceedings of the Eighth Vertebrate Pest Conference, 7-9 March. Vol. 19, Sacramento, CA, pp. 245-256.

Evans, J., 1987. Mountain beaver damage and management. In: Proceedings of the Symposium on Animal Damage Management in Pacific Northwest Forests, Spokane, Washington, pp. 74-74.

Feldhamer, G.A., Rochelle, J.A., 1994. Mountain beaver. In: Chapman, J.A., Feldhamer, G.A. (Eds.), Wild Mammals of North America: Biology, Management, and Economics. The John Hopkins University Press, Baltimore, pp. 167-175.

Hadler, M.R., Buckle, A.P., 1992. Forty-five years of anticoagulant rodenticides - past, present, and future trends. In: Borrecco, J., Marsh, R.E. (Eds.) Proceedings of the 15th Vertebrate Pest Conference, 3-5 March 1992. Vol. 15, Newport Beach, CA, pp. 149-155.

Hooven, E.F., 1977. The mountain beaver in Oregon: its life history and control. Oregeon State University Forestry Research Lab. Research paper 30, 20pp.

Hosea, R.C., 2000. Exposure of non-target wildlife to anticoagulant rodenticides in California. In: Salmon, T.P., Crabb, A.C. (Eds.), Proceedings of the 19th Vertebrate Pest Conference, 6-9 March 2000. Vol. 19, San Diego, CA, pp. 236-244.

Kaukeinen, D., 1982. A review of the secondary poisoning hazard potential to wildlife from the use of anticoagulant rodenticides. In: Marsh, R.E. (Ed.), Proceedings of the 10th Vertebrate Pest Conference, 23-25 February 1982. Vol. 10, Monterey, CA, pp. 151-158.

Kaukeinen, D.E., Spragins, C.W., Hobson, J.F., 2000. Risk-benefit considerations in evaluating commensal anticoagulant rodenticide impacts to wildlife. In: Salmon, T.P., Crabb, A.C. (Eds.) Proceedings of the 19th Vertebrate Pest Conference, 6-9 March 2000. Vol. 19, San Diego, CA, pp. 245-256.

Lowenthal, J., Rivera, G.M.V., 1979. Comparisons of the activity of the cis and trans isomer of vitamin $\mathrm{K}_{1}$ in vitamin $\mathrm{K}$-deficient and coumarin anticoagulant-pretreated rats. J. Pharmacol. Exp. Ther. 209, 330-333.

Murphy, E.C., Clapperton, B.K., Bradfield, P.M.F., Speed, H.J., 1998. Effects of rat-poisoning operations on abundance and diet of mustelids in New Zealand podocarp forests. New Zealand J. Zoo. $25,315-328$.

Nelson, W.E., 1969. Operation of animal-control practices. In: Proceedings of the Symposium on wildlife and Reforestation in the Pacific Northwest, Oregon State University, Corvalis, OR, pp. 75-76.

Nemdenhall, V.M., Pank, L.F., 1980. Secondary poisoning of owls by anticoagulant rodenticides. Wildl. Soc. Bull. 8, 311-315.

Nolte, D.L., 1998. Wildlife considerations when planning plant projects. In: Rose, D., Rose, R. (Eds.), Native Plants: Propagation and Planting. Oregon State University, Corvallis, OR in press.

Record, C.R., Marsh, R.E., 1988. Rodenticides residue in animal carcasses and their relevance to secondary hazards. In: Crabb, A.C., Marsh, R.E. (Eds.), Proceedings of the 13th Vertebrate Pest Conference, 1-3 March 1988. Vol. 13, Monterey, CA, pp. 163-168.

Silverman, R.B., 1980. A model for the molecular mechanism of anticoagulant activity of 3-substituted 4-hydroxycoumarins. J. Am. Chem. Soc. 102, 5421-5423.

Tickes, B.R., Cheathean, L.K., Stair, J.L., 1980. A comparison of selected rodenticides for the control of the common valley pocket gopher (Thomomys bottae). In: Clark, J.P. (Ed.), Proceedings of the 10th Vertebrate Pest Conference, 4-6 March 1980, Vol. 10, Fresno, CA, pp. 201-204.

Timm, R.M., 1994. Description of active ingredients: anticoagulants. In: Hygnstrom, S.E., Timm, R.M., Larson, G.E. (Eds.), Prevention and Control of Wildlife Damage. University of Nebraska Cooperative Extension, Lincoln, Nebraska, pp. G26-G29. 